\title{
Combined Photovaporization of Prostate and Laser Cystolithotripsy Using GreenLight Laser
}

\section{Darren Ow, MBBS}

Department of Surgery, University of Melbourne, Melbourne, Australia. Young Urology Researchers Organisation (YURO), Melbourne, Australia. E-mail: okhdarren@gmail.com

\section{Daniel Christidis, MBBS}

Department of Surgery, University of Melbourne, Melbourne, Australia. Young Urology Researchers Organisation (YURO), Melbourne, Australia.

\section{Marlon Perera, MBBS, BMedSci}

Department of Surgery, University of Melbourne, Melbourne, Australia. Young Urology Researchers Organisation (YURO), Melbourne, Australia.

\section{Damien M. Bolton, MBBS, MD, FRACS}

Department of Surgery, University of Melbourne, Melbourne, Australia.

Olivia Newton-John for Cancer Research Institute, Heidelberg Branch, Austin Health, Melbourne, Australia.

\section{Nathan Lawrentschuk, MBBS, PhD, FRACS}

Department of Surgery, University of Melbourne, Melbourne, Australia.

Olivia Newton-John for Cancer Research Institute, Heidelberg Branch, Austin Health, Melbourne, Australia.

Department of Surgical Oncology, Peter MacCallum Cancer Centre, Melbourne, Australia.
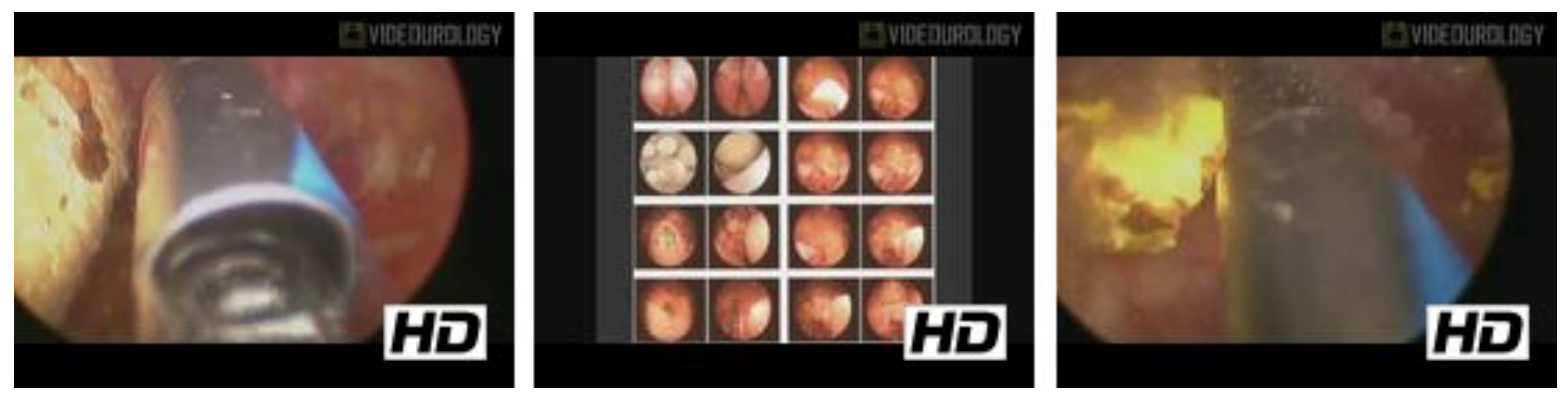

\section{Abstract}

Objective: Laser cystolithotripsy $(\mathrm{CL})$ using holmium laser represents a recommended treatment option for patients with bladder calculi. 1,2 However, to date, no study or technique has reported the use of laser CL on bladder calculi using GreenLight ${ }^{\top \mathrm{M}}$. This study demonstrates the safety and feasibility of using this surgical technique step-by-step by performing photovaporization of the prostate (PVP) as well as laser CL of both prostate and bladder calculi simultaneously in a single operation as an alternative method by utilizing GreenLight laser only.

Patients and Methods: This video illustrates a stepwise approach for PVP and followed by CL. We report our single surgeon's initial experience with this technique using 532-nm lithium triborate laser (GreenLight XPS 180W device; Boston Scientific, Marlborough, MA) to perform both procedures. Patients with significant bladder outlet obstruction secondary to prostate hyperplasia with presence of bladder calculi underwent both PVP and CL in a single operation. Patients who underwent CL using other methods were excluded from this study. Bladder calculi were disintegrated to smaller fragments, allowing 
passage of stone postprocedure. Routine postprocedure catheterization was performed and followed by removal of catheter the next day.

Results: The prostate was initially photovaporized on lateral lobes and subsequently on median lobe. Once a clear passage of the prostatic urethra has been formed, laser CL was then performed. Laser energy was reduced from 180 to $120 \mathrm{~W}$ for stone fragmentation. Smaller stone fragments can be repositioned at the prostatic fossa to allow easier laser CL of the bladder calculi as the GreenLight laser possesses the side firing arm, thus making easier further stone fragmentation and could potentially avoid bladder injury.

Conclusions: The GreenLight laser appears to be safe and can be an alternative method for treating both prostate hyperplasia and bladder calculi in a single operation. The advantages of using this method are minimal invasiveness and cost effectiveness. A single intervention approach to treat both diseases is deemed useful and has proven that this method is safe and can potentially avoid invasive procedures. Further research is required to definitively determine the safety of this technique.

No competing financial interests exist.

Runtime of video: 6 mins 52 secs

Keywords: laser cystolithotripsy, photovaporization, bladder calculi, prostate

\section{Cite this video}

Darren Ow, Daniel Christidis, Marlon Perera, Damien M. Bolton, Nathan Lawrentschuk, Combined Photovaporization of Prostate and Laser Cystolithotripsy Using GreenLight Laser, Videourology. 2017, DOI: $10.1089 /$ vid.2017.0017.

\section{References}

1. Shah HN, Hegde SS, Shah JN, Mahajan AP, Bansal MB. Simultaneous transurethral cystolithotripsy with holmium laser enucleation of the prostate: A prospective feasibility study and review of literature. BJU Int 2007;99:595-600.

2. Nameirakpam S, Naorem S, Faridi MS, Akoijam KS, Sinam RS. Transurethral cystolithotripsy of large bladder stones by holmium laser as a day care procedure. J Clin Diagn Res 2016;10:PC01-PC02.

Original Publication Date: 2017 